\title{
Optimization Techniques of Decision Making - Decision Tree
}

\author{
Cezarina Adina TOFAN \\ cezarina_adina@yahoo.com
}

\begin{abstract}
Modern methods of modeling and simulation of manufacturing processes inevitably lead to a tendency to standardize management judgment to perception phenomena specific industrial management and performance of decision-making. Considering that what happens in a production system similar repeated in other similar systems, identifying an acceptable method of solving problems categories, adopting the same decision in similar situations is convenient and prompt. However, every problem has a unique character management undisputed that a number of specific elements have content, performance or behaviors different single generalized model, the manager must identify those features that lead to the conclusion that every problem, at least partially, is a special case, singular. The realities of the modern society shows us that with the development of the market economy and its increasing complexity, the economic information has to develop appropriately, because it can provide the necessary elements to make decisions, to be able to reflect exactly the patrimonial situation of the economic operators and the economic and financial results, the main objective is to increase the firm value. Management through functions and its attributes is what determines the business objectives, the necessary resources to achieve them and the distribution of the results created by using of these resources. The raw materials that constitute the basis of the management are information and people'.
\end{abstract}

Keywords: management methods, decisions

\section{INTRODUCTION}

Materialization of the management process involves four subsystems:

Organizational subsystem provides division, combination, functioning of the work processes as an important prerequisite for achieving the objectives;

Information subsystem represents all data, information, circuits and information flows, procedures and means of information processing aimed at the foundation, setting and achieving the goals system of the organization;

Decision-making subsystem encompasses all the microeconomic decisions and the substantiating, adopting and implementing mechanisms of them;

Methodological subsystem is reflected by the systems, methods, techniques, procedures, and rules used in the performance the management process and its functions.

1 Tofan C. A., Data base concerning the costing management, Economic Science Series (Annals of Spiru Haret University. Economic Sciences Series), issue: XV / 2009, pg: 511-514. 
Quality of information is a factor that directly affects the quality of the conducted management analyzes and generates the competent decisions ${ }^{2}$.

Importance of the decision lies in the fact that it is found interconnected with all the management functions (Figure 1).

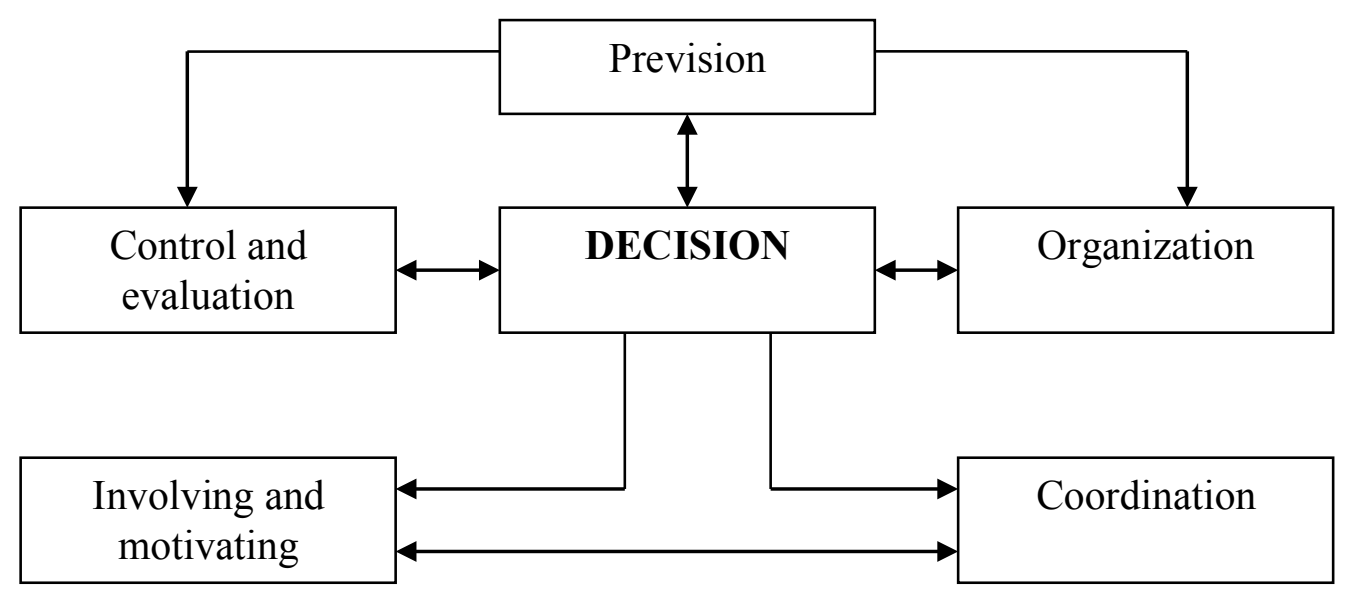

Figure 1. Interconnection of the decision at the management functions

The decision can be defined as the chosen way from several possible to achieve an objective. Quality and the value of the taken decisions by the decision-making system depend on the quality of information. The qualitative characteristics of information can be minimized by the operations to which they are subject, starting with collecting, then through processing and ending with their submission. Thus, the information system is dependent not only on the content, type and the amount of information handled by it but also on the quality of changes which they have undergone.

\section{Adopting the decision using the decisional tree}

\section{MATERIALS AND METHOD}

Decisions with the random universe are characterized by the following elements: factors and decisional consequences are not known perfectly, there are a multitude of consequences and there is possibility to assign a probability to each consequence.

Probability calculation allowed determining the optimal alternative that maximizes the economic function determined by the decision maker. In this case, the decision criterion is the mathematical expectancy that applies to the repetitive decisions.

Function to calculate the mathematical expectancy of winning is calculated using the formula:

$$
E_{m j}=\sum_{j=1}^{n} p_{j} * R_{i j}
$$

In which:

$E_{m j}$ is the mathematical expectancy of gain for the $i$ decision (i version)

$p_{j}$ is the probability of achieving of the $j$ criterion results

$R_{i j}$ symbolizes the result for $p_{j}$ probability

2 Tofan C. A., The management of the informatics systems projection, Review of General Management, Brasov, vol. 10(2), pg. 40-49, 2009. 
Within the enterprises, the types of economic problems which have a random future are very numerous. The complex situations benefit of achieving good results, for determining the optimal decision using the decisional tree method.

Steps that should be taken to implement the decisional tree method $\operatorname{are}^{3}$ :

○ Defining the decisional problem to be optimized and the main events that probabilistic influence the decisional consequences;

- Graphical representation of the tree, which is consisted alternatively by the decision and hazard periods;

- Determining the decisional consequences for each alternative using the probabilities of occurrence and manifestation of the events. Probabilities are determined by statistical, analytical or empirical methods and the decisional consequences are type of profit, cost, productivity, production capacity, level of sales, etc.

- Choosing the optimum by calculating the mathematical expectancy for each consequence and alternative decision. The optimal variant would be one that has higher mathematical expectancy value.

The decision tree is used for the complex decisions such as those for the investment optimization, assimilating in manufacturing of a new product, selling products and others.

\section{Adopting the decision using the decisional tree method - the case study}

An enterprise that has as main activity the production of parts for the machine building industry wants to introduce a new product on the market. To assess the launch on the market, from the competition point of view, we have the market variant with high competition and the market variant with low competition. To achieve the decision tree, there was used as an average price for one unit, the price of 24 euro / piece at a monthly sales volume between 250 and 300 pieces.

If the product is launched on the market with high competition, we have two situations: the main competitors to react to the emergence of the new product and to intensify the promotion, case with a probability $\mathrm{p}=0.6$ or competitors do not react, in which case $\mathrm{p}=0.4$.

Depending on the reaction of the main competitors, where they will react, the firm will act in a proper pricing policy, with the prices below the average and maintaining sales volume $(\mathrm{p}=03)$, in which it would have a sale of 7200 euro/month, or it will keep the stable average price, but will decrease the volume of sales, in which case the sale would be 5700 euros/month.

If the competition does not respond, it will be kept a moderate price and the weighted sales volume, case with $\mathrm{p}=0.6$ and a sale of 6600 euro/month.

For the situation when the company would choose to sell the product in a market where the competition is low, the implemented decisions would be to increase the sale of products at a lower price than the competition $(\mathrm{p}=0.5)$, or to increase the volume of sales at a similar price to that of the market. Depending on the response of the competition it may choose to maintain the average price and an increased sales volume in the case when the competition does not respond $(\mathrm{p}=0.7)$, or to maintain the high volume of sales at a price below the competition price, in which the sale would be of 7500 euros/month.

\footnotetext{
3 Rațiu-Suciu C., Modelare economică, ASE Publishing House, Bucharest, 2007, pg. 286.
} 
Decisions, the competitor reactions and the appropriate results for each probability and the probability that an event will happen, there are shown directly on the decision tree shown in Figure 2.

In this tree there are used the following notations:

- Roads (arcs) symbolized by a square and marked with numbers ( $0 \ldots 4 \ldots 20)$, corresponding to the company decisions;

- Roads (arcs) symbolized by a circle and marked with letters (A, B ... J), corresponding to the interventions chance, respectively the reaction of competition;

- $\mathrm{p}=$ probability;

- $\mathrm{R}=$ net result of the decision for the period;

- Increased competition (CS), low competition (CS) decision alternative of the enterprise or of the competition.

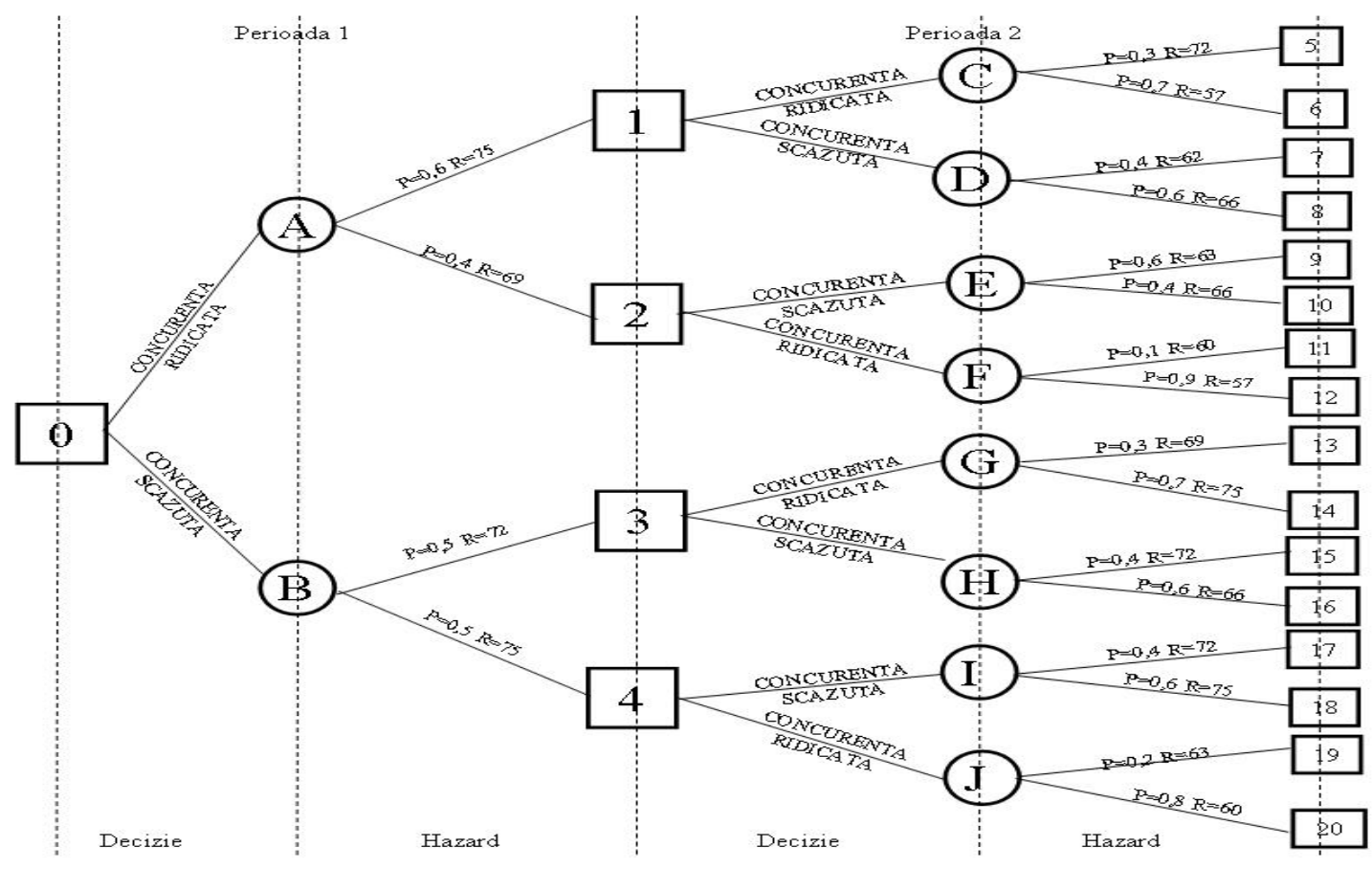

Figure 2. Decisional tree

Based on the presented data it can be determined the decision that may be taken. For this we calculated the value of each road that lead to the original decision.

For each stage, there is calculated the expectancy of gain (E) from the end of the graph, by applying the formula (1.1):

$$
\begin{aligned}
& \mathrm{E}(\mathrm{C})=0.3 * 72+0.7 * 57=60.8 \\
& \mathrm{E}(\mathrm{D})=0.4 * 62+0.6 * 66=64.4 \\
& \mathrm{E}(\mathrm{E})=0.6 * 63+0.4 * 66=64.2 \\
& \mathrm{E}(\mathrm{F})=0.1 * 60+0.9 * 57=57.3 \\
& \mathrm{E}(\mathrm{G})=0.3 * 69+0.7 * 75=73.2 \\
& \mathrm{E}(\mathrm{H})=0.4 * 72+0.6 * 66=68.4 \\
& \mathrm{E}(\mathrm{I})=0.4 * 72+0.6 * 75=73.8 \\
& \mathrm{E}(\mathrm{J})=0.2 * 63+0.8 * 60=60.6
\end{aligned}
$$


After the calculations, it results that a number of roads can be removed. If the company leaves from point 1 , it is clear that we must choose the road $D$ because the mathematical expectancy value is greater than 64.4> 60.8. So, it is eliminated the C5 and C6.

A similar procedure is applied to others possibilities and the tree is simplified. So, it results a simplified tree shown in the following figure:

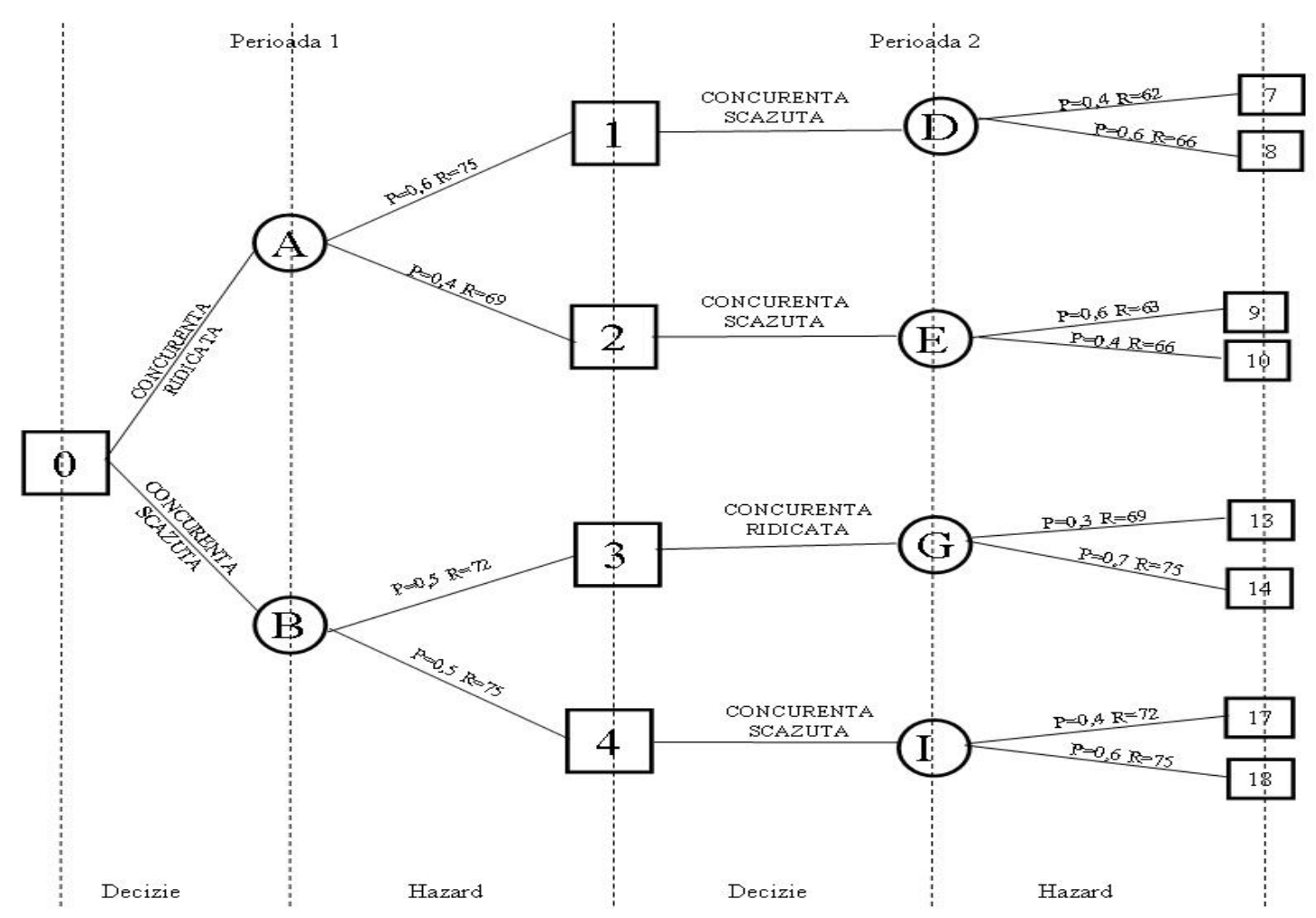

Figure 3. Decisional tree after eliminating of some branches resulted from calculations

$$
\begin{aligned}
& \mathrm{E}(\mathrm{D})=0.4 * 62+0.6 * 66=64.4 \\
& \mathrm{E}(\mathrm{E})=0.6 * 63+0.4 * 66=64.2 \\
& \mathrm{E}(\mathrm{G})=0.3 * 69+0.7 * 75=73.2 \\
& \mathrm{E}(\mathrm{I})=0.4 * 72+0.6 * 75=73.8
\end{aligned}
$$

Thus, it can be calculated the expectancy of gain for every road to the end of the first period (in $A$ and $B$ ):

$$
\begin{aligned}
& E(A)=0,6 * E(A, D)+0,4 * E(A, E)=0,6(75+64,4)+0,4(69+64,2)=137,92 \\
& E(B)=0,5^{*} E(B, G)+0,5^{*} E(B, I)=0,5(72+73,2)+0,5(75+73,8)=147,3
\end{aligned}
$$

The tree can be simplified further and result the situation from the following figure: 


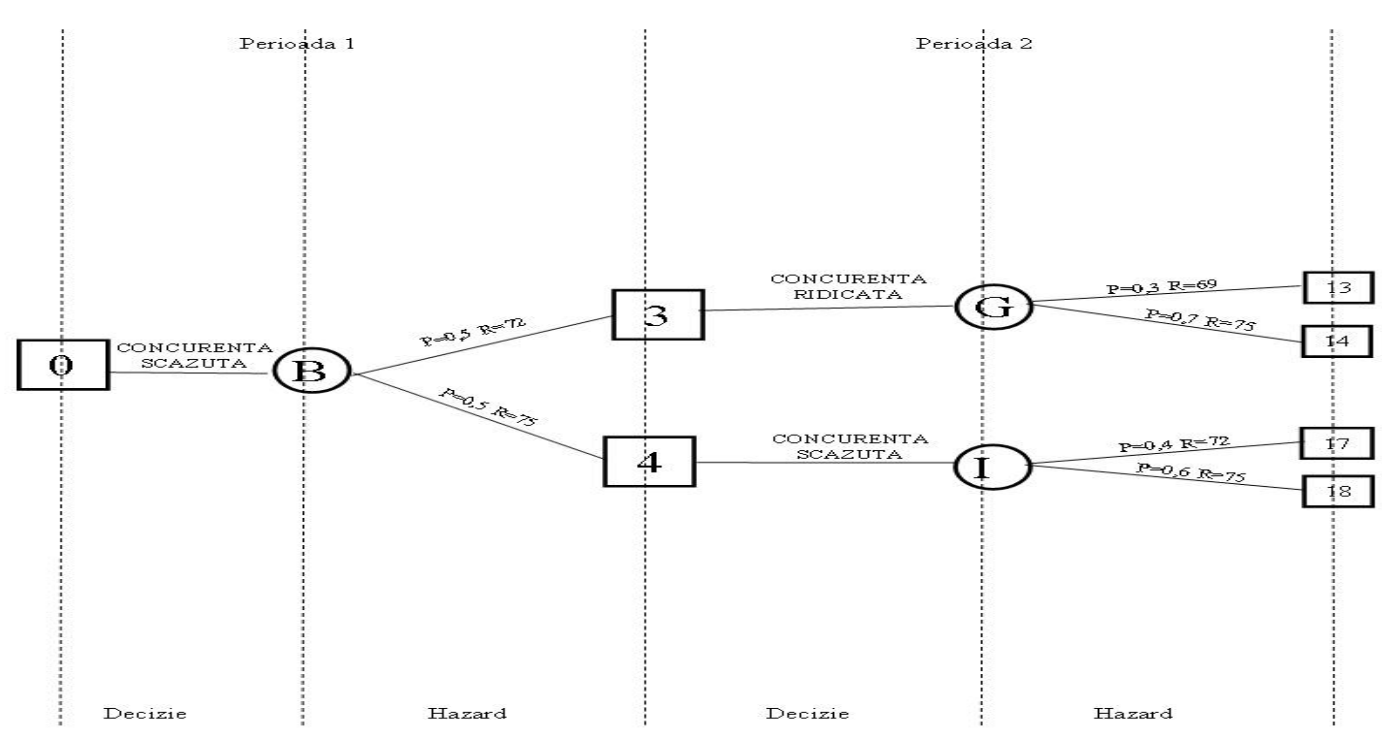

Figure 4. Decisional tree after eliminating of some branches resulted from the expectancy of gain calculations

It can be concluded that the tree allows taking the first optimal decision, so the company must enter on the market with the low competition, because the expectancy of gain is of 147.3 to 137.92 for the market with high competition.

The following decisions are conditioned by the competition reaction. Thus, if the competition reacts (point 3), the company will have to fight back by decreasing the price over the competition, keeping constant the sales volume, and where competition does not react (point 4), the company will keep the sale volume and simultaneously will be able to increase the price over the competition.

Actually, the uncertain and changing environments, in which the companies operate, lead to the occurrence of very many unforeseeable situations and indicated to substantiate scientifically the decisions.

The decisional tree method is applied in situations when the hazard periods (risk) succeeding the decision periods, with several possible consequences, which may be associated a probability.

The probability of the risk represents the possibility that risk to occur. According to the probability theory, it is called the probability of the event A (denoted by $\mathrm{P}(\mathrm{A})$ ) the ratio between the $m$ number of the favourable results for occurring the event $A$ and the total number $n$ of the experimental results considered equally possible (all the results are possible):

$$
P(A)=\frac{m}{n}
$$

Where:

$m=$ number of favourable results for occurring the event $\mathrm{A}$

$n=$ total number of experimental results considered equally possible (all results are possible)

The impact of the risk indicates the effect of the risk on the organization's objectives if it is manifested. The probability and the impact of the risk are assessed as: 
○ High,

- Moderate,

○ Low.

To perform the matrix of the risk score, it is used to calculate the risk score the following formula:

$$
\text { Risk Score }=\text { Probability } \mathrm{x} \text { Impact }
$$

To determine the scores for each risk, it is drawn up the matrix of the risk score according to the table Example 1.

Table Example One Matrix of the risk score

\begin{tabular}{|c|r|r|r|r|r|}
\hline \multirow{2}{*}{ Probability } & \multicolumn{6}{|c|}{ Impact of the risk } \\
\cline { 2 - 6 } & $\mathbf{0 . 0 5}$ & $\mathbf{0 . 1}$ & $\mathbf{0 . 2}$ & $\mathbf{0 . 4}$ & $\mathbf{0 . 8}$ \\
\hline $\mathbf{0 . 9}$ & 0.045 & 0.09 & 0.18 & 0.36 & 0.72 \\
\hline $\mathbf{0 . 8}$ & 0.04 & 0.08 & 0.16 & 0.32 & 0.64 \\
\hline $\mathbf{0 . 7}$ & 0.035 & 0.07 & 0.14 & 0.28 & 0.56 \\
\hline $\mathbf{0 . 6}$ & 0.03 & 0.06 & 0.12 & 0.24 & 0.48 \\
\hline $\mathbf{0 . 5}$ & 0.025 & 0.05 & 0.1 & 0.2 & 0.4 \\
\hline $\mathbf{0 . 4}$ & 0.02 & 0.04 & 0.08 & 0.16 & 0.32 \\
\hline $\mathbf{0 . 3}$ & 0.015 & 0.03 & 0.06 & 0.12 & 0.24 \\
\hline $\mathbf{0 . 2}$ & 0.01 & 0.02 & 0.04 & 0.08 & 0.16 \\
\hline $\mathbf{0 . 1}$ & 0.005 & 0.01 & 0.02 & 0.04 & 0.08 \\
\hline
\end{tabular}

Score $<0.05$ - low impact (green)

$0.05<=$ Score $<0.15$ - moderate impact (yellow)

Score $>=0.15$ - high impact (red).

\section{CONCLUSION}

Through the quantitative analysis aims the numerical evaluation of the probability and impact of each risk on the organization's objectives. With this method there are represented the decisions and the random events as they are perceived by the decision makers.

This paper has been financially supported within the project entitled "Horizon 2020 Doctoral and Postdoctoral Studies: Promoting the National Interest through Excellence, Competitiveness and Responsibility in the Field of Romanian Fundamental and Applied Scientific Research", contract number POSDRU/159/1.5/S/140106. This project is co-financed by European Social Fund through Sectoral Operational Programme for Human Resources Development 2007-2013. Investing in people!

\section{References:}

1. Rațiu-Suciu C., Modelare economică, ASE Publishing House, Bucharest, 2007

2. Tofan C. A., Data base concerning the costing management, Economic Science Series (Annals of Spiru Haret University. Economic Sciences Series), issue: XV / 2009

3. Tofan C. A., The management of the informatics systems projection, Review of General Management, Brasov, vol. 10(2), 2009.

4. Tofan C. A., Information system - a component of the management system, Review of General Management, Spiru Haret University, Faculty of Management Brasov, vol. 17, Issue 1, 2013 